\section{A PARADIGM SHIFT IN STERILISATION}

Metafix (UK) Ltd is introducing new technology to the British market for the sterilisation of dental instruments and handpieces, providing the shortest cycle times, simplicity of use and significant reduction in energy costs: six minutes - unwrapped instruments; eight minutes unwrapped handpieces; 12 minutes - wrapped instruments and handpieces.

Unlike an autoclave, no steam or vacuum is required, so you can say goodbye to filling and draining the steriliser with costly

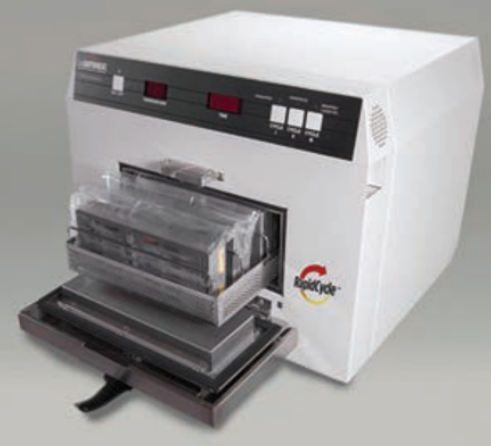

\section{LEAVE BIOFILM DEAD IN THE WATER}

For almost ten years, CleanCert has been providing dental practices and laboratories with effective and 'easy to use' infection control solutions.

CleanCert+ biofilm cleaner, for example, is a revolutionary one-stage waterline cleaner that is independently proven to be efficacious, as well as safe and simple to use. Used just once a week for five minutes (using reverse osmosis or distilled water the rest of the time) and priced at only $£ 41$ for a six-month supply for one dental chair, it offers incredible value and unrivalled safety (MSDS).

LabCert, meanwhile, is a powerful and highly effective ready-to-use disinfectant, which can be employed on all materials and appliances that are transferred between dental practices and laboratories, ensuring the wellbeing of staff and patients alike in all premises.

For further information on how to simplify your infection control HTM 01-05 'best practice' compliance with the full range of proven, innovative dental infection control and water purification products available from CleanCert, visit cleancert.co.uk, email sales@cleancert. co.uk or call 08443511115 . deionised or RO water and no drying cycle or wet instruments.

The technology employed by the manufacturer CPAC Equipment Inc. uses High Velocity Hot Air (HVHA), a forced air heat exchange process that induces rapid air movement (up to $3000 \mathrm{ft} /$ minute) at $190 \mathrm{C}$ to efficiently sterilise instruments. HVHA rapid sterilisation eliminates excessive heating - the prime cause of instrument damage.

HVHA technology enables longer instrument life, maintaining instrument sharpness with no dulling, pitting or corrosion caused by steam in autoclaving.

Load capacity for the Cox RapidHeat HVHA steriliser using double-decker cassettes is more than 200 instruments per hour and the all new HV-Pro11 has four times this capacity.

Contact Greg Jackson at Metafix on 01933 461907 or visit www.metafix.co.uk.

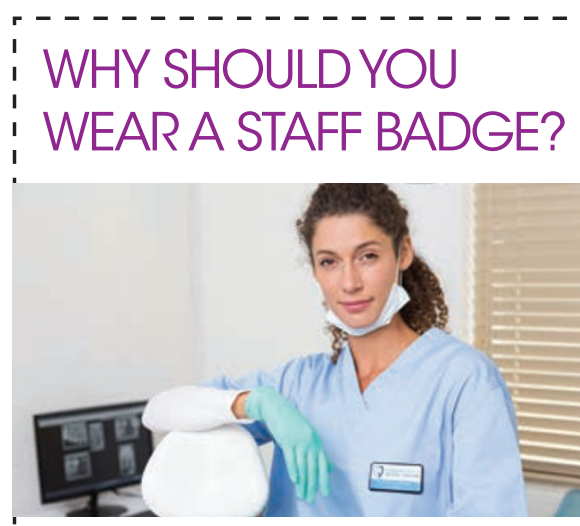

There are five key reasons why your dental

team might choose to wear a staff badge:

1. Professional image - A staff badge will give a sense of professionalism and high standards

2. Creates a great first impression - You only get one chance to make a first impression, I make it count

3. Approachability - Patients feel more comfortable and will engage more with named members of staff

4. Accountability - Encourages staff to perform well as an ambassador of the company

5. Brand/corporate awareness - The use of logo, type and colour can all be integrated to help promote and instil your company branding.

There are other excellent reasons to wear a staff badge, including security, trust, sense of team spirit and service feedback. www.staffbadgesdirect.co.uk.

\section{THE WORLD'S FIRST ADULT TEETHER}

A dental

student has

invented the world's first

adult teether

- to combat

the agony

of problem

wisdom teeth.

Jeevan Boyal

came up with

the EZ Teether

after spotting a

baby sucking on

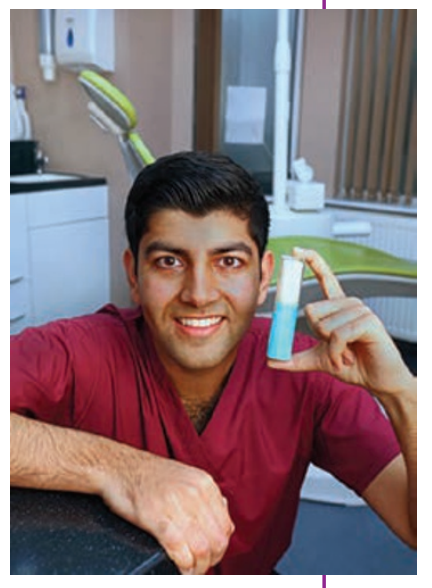

a teething aid while he was suffering with

his own painful wisdom teeth.

The 21-year-old University of Sheffield dentistry student had been surprised to discover that there was little help available for painful wisdom teeth. The baby in the pram inspired his idea for an adult teether.

He went away and designed his own device based on angles for the jaw and mouth set out in his dentistry textbooks. Now he is selling his device, trademarked as the EZ Teether, on his own website EZteether.com, at $£ 12.99$ each, as well as through online retailer Amazon.

While the teether contains no painkillers, the action of biting down on its rubber-like surface provides instant pain relief to irritable wisdom teeth. The device acts in the same fashion as a child's teething aid, and works by massaging the affected gums to ease discomfort.

Jeevan hopes the adult teether will be popular with other young adults and could also make a useful gift choice for parents keen to pack their sons and daughters off to university with everything they could possibly need.

The EZ Teether is $11 \mathrm{~cm}$ long with a plastic handle and a Santoprene biting surface. Each device weighs just 35 grams.

For more information about the EZ Teether device visit www.EZteether.com 